\title{
Free living soil Nematodes as Ecological Indicators
}

\author{
Daya Ram Bhusal \\ Central Department of Zoology, Tribhuvan University, Kirtipur Kathmandu, Nepal
}

For correspondence: drbhusal@cdztu.edu.np

\begin{abstract}
Free living Nematodes communities used as bioindicators of soil health because their composition well correlates with, two critical ecological processes i.e. nitrogen cycling and decomposition in soil . Nematodes indices withstand statistical rigor better than abundances, proportions, or ratios of trophic groups. Nematodes indices respond to a variety of land-management practices, based largely on life history characteristics of families.
\end{abstract}

Key words: soil, bioindicator, nematodes indices, monitoring, trophic diversity

\section{Introduction}

The importance of soil organisms for maintaining soil functionality and regulating processes that support ecosystem services, like nutrient and water retention, carbon storage and pest resistance, is widely recognized (Wall 2012 and Mulder et al. 2011). Among soil biota nematodes are among the most thoroughly studied groups as they combine several unique characteristics. They occur in high diversity and density in every soil and sediment type (Treonis and Wall 2005 and Wu et al. 2011) and are very diverse in terms of trophic preferences, represent all trophic groups and levels in the soil food web (Bongers and Ferris 1999 and Yeates 2003) and have variable life history strategies (Bongers 1990). They are involved in fundamental ecological processes like decomposition and nutrient cycling (de Goede and Bongers 1994) and their functional composition is indicative of the major channels of matter and energy transfer across the decomposition pathways. Nematodes have a permeable cuticle, which allows them to respond with a range of reactions to pollutants (Wasilewska 1994). Some nematodes have resistant stages such as cryptobiotic forms or cysts that allow them to survive inactively during unfavorable environmental conditions for growth. However, some nematode taxa such as Dorylaimidae have no resistant stages, which may make them more sensitive to environmental change (Bongers 1999). Thus, nematode community structure is a sensitive indicator of the soil status and environmental disturbances (Bongers and Bongers 1998) and nematodes are among the most preferred bioindicators of soil condition (Bongers and Ferris 1999, Zhao and Neher 2005). The composition of soil nematode communities is influenced by environmental variables such as vegetation, soil type, season, soil moisture level and soil organic matter content (Goralczyk 1998). In many cases there are strongly related with specific microhabitats or with specific hosts in the case of parasitic nematodes (Pinto et al. 2006).

\section{Feeding groups (Trophic groups)}

The allocation of nematodes to feeding groups is an effective method to condense information. Yeates et al. (1993) published a synthesis in which the following groups were distinguished: 1. Plant feeding (Sedentary parasites, Migratory endoparasites, Semi-endoparasites, Ectoparasites i.e. Epidermal cell and root hair feeders, Algal and moss feeders, Feeders on plant tissues eg- Tylenchidae, Psilenchidae, Atylenchidae; Tylenchus, Laimaphelenchus, Anguinidae). 2. Bacterial feeding group i.e. cephalobidae,

Nepalese Journal of Zoology | Online Volume 3 Issue 1 | November 2015 | Page 59 
Plectidae etc 3. Fungal feeding group eg. Aphelenchidae - Aphelenchoides 4. Predators groups egMononchidae, Longidoridae 5.Omnivorous (both predators as well as plant feeders)eg- Qudsianematidae, Thornematidae etc.

\section{Colonizer persister (C-P)}

Based on life strategy Bongers (1990) allocated terrestrial and freshwater nematodes on a continuum from colonizers to persisters ( $r$ - to K-strategists) followed by a similar proposal for marine nematodes (Bongers et al., 1991). The following groups can be distinguished on the colonizer-persister (cp) scale. These are used to indicate the soil status.

cp-1 group: Nematodes with a short generation time, producing many small eggs resulting in an explosive population growth under food-rich conditions, for example, bacteria blooming in enriched soils. They are relatively tolerant to pollution-induced stress. for example, Rhabditidae. Obviously they have a high metabolic activity. These enrichment opportunists show a phoretic relation with insects and other vectors and are only active under transient conditions of high microbial activity, they form

cp-2 groups: Nematodes with a short generation time and a high reproduction rate, but do not form dauerlarvae. They occur under food-rich as well as food-poor conditions and are very tolerant to pollutants and other disturbances. This group is composed of the smaller tylenchids, mainly feeding on epidermal cells; The fungal feeding aphelenchoids and anguinids and the bacterial feeding cephalobids, plectids and monhysterids.

cp-3 groups: They have a longer generation time and are relatively sensitive to disturbances. This group is composed of the bacterial feeding teratocephalids, the Araeolaimida and Chromadorida; the larger tylenchid nematodes that feed on deeper cell layers in the roots; the diphtherophorids, assumed to feed on fungi, and the carnivorous tripylids.

cp-4 groups: Small dorylaimids and large non-dorylaimids. These nematodes are characterized by a long generation time, permeable cuticle and sensitivity to pollutants. The non-carnivorous nematodes in this group are relatively sessile, whereas carnivorous have to move. This group is composed of larger carnivores, the bacterial feeding Alaimidae and Bathyodontidae, the smaller Dorylaimid nematodes and the plant feeding trichodorids.

cp-5 groups: Large dorylaimid nematodes with a long life span and low reproduction rate; both probably a corollary of low metabolic activity, highly sensitive to disturbance.

\section{Nematode community indices}

For the evaluation of soil conditions, well documented nematological indices have been developed for this purpose ( Bongers 1990, 1993, Bongers and Ferris 1999, Ferris et al. 2001, Verschoor et al. 2001, Yeates 2003, 2007) and successfully applied to monitor land use changes, management effects, environmental disturbance and pollution among others (Tsiafouli et al. 2007; Vonk et al. 2013). According to Neher et al. (2005), nematode indices are cost-effective, easy to calibrate and interpret.

\section{Nematological indices}

Maturity index (MI): Bonger (1990) proposed maturity index for free-living taxa. It is viewed as a measure of disturbance, with smaller values being indicative of a more disturbed environment and larger values characteristic of a less disturbed environment. Yeates' (1994) proposed modification of the index based on merging free-living and plant parasitic nematodes (PPI) for the summed of (SMI).

Nepalese Journal of Zoology | Online Volume 3 Issue 1 | November 2015 | Page 60 
Enrichment index (EI). Enrichment index (Ferris et al. 2001) is based on the expected responsiveness of the opportunistic guilds (bacterivorous nematodes with c-p1) to organic resources enrichment. The enrichment-opportunist bacterivorous nematode guild includes species in the families Rhabditidae, Panagrolaimidae and Diplogasteridae (Bongers and Ferris 1999, Ferris et al. 2001). Therefore, EI describes whether the soil environment is nutrient enriched (high EI) or depleted (low EI). Food webs become enriched when disturbance occurs. Resources become available due to external input, organism mortality, turnover, or favorable shifts in the environment.

Structure index (SI): The SI (Ferris et al. 2001) represents an aggregation of functional guilds with c-p values ranging from 3-5 and describes whether the soil ecosystem is structured with greater trophic links (high SI) or degraded (low SI) with fewer trophic links. Similarly, Plotting of EI vs. SI provides a model framework of nematode faunal analysis as an indicator of the likely conditions of the soil food web.

Channel index (CI). The CI (Ferris et al. 2001) is a percentage of fungivores among the total fungivores and c-p 1 bacterivorous. It indicates predominant decomposition channels in the soil food web. A high CI (>50\%) indicates fungal decomposition channels whereas low CI $(<50 \%)$ suggests bacterial decomposition channels. The $\mathrm{CI}$ also provides a means of tracking succession between fungivorous and bacterivorous nematodes as organic resources are supplied and depleted in agricultural systems. Decomposition rates of readily degraded material in bacterial pathways are expected to be faster than that in fungal pathways where materials may be more complex. Due to the similarity of $\mathrm{C} / \mathrm{N}$ ratios of fungi and fungivorous nematodes, mineralization rates in fungal channels should be slower than those in bacterial channels.

Basal index (BI): The BI is based on the proportion of bacteria-feeding and fungi-feeding nematodes with a c-p value of 2. It also indicates predominant decomposition channels in the soil food web.

Nematode Metabolic footprints (MF) indices: These are the more recent set of indices (Ferris, 2010) that refer to carbon utilization by nematodes. The metabolic footprint of component taxa, is the sum of the lifetime amount of $\mathrm{C}$ partitioned into growth, egg production and respiration which is the amount of $\mathrm{C}$ utilized in metabolic activity. MF gives insight to the nature but also the magnitude of soil functions. MF are calculated for each trophic group (bacteriovore MF, fungivore MF, herbivore MF, omnivore MF and predatory MF).

\section{References}

Bongers, T. 1990. The maturity index: an ecological measure of environmental disturbance based on nematode species composition. Oecologia 83: 14-19.

Bongers, T. Ferris, H. 1999. Nematode community structure as a bioindicator in environmental monitoring. Trends Ecol Evol 14: 224-228.

Bongers, T., Bongers, M. 1998. Functional diversity of nematodes. Appl Soil Ecol 10: 239-251. de Goede, R.G.M., Bongers, T.1994. Nematode community structure in relation to soil and vegetation characteristics, App Soil Ecol 1: 29-44.

Ferris, H., Bongers, T., de Geode, R.G.M. 2001. A framework for soil food web diagnostics: extension of the nematode faunal analysis concept. Appl. Soil Ecol 18: 13-29.

Goralczyk, K. (1998). Nematodes in a coastal dune succession: Indicators of soil properties? Applied Soil Ecology 9: 465-469.

Nepalese Journal of Zoology | Online Volume 3 Issue 1 | November 2015 | Page 61 
Mulder, C., Moit, A., Bonkowski, M., Peter, C., de Ruiter, P.C., Mancinelli, G., Marcel, G,A., Heijden, V.D., Harm, J., Wijnen,V., Vonk, A., Rutgers, M. (2011). A Belowground Perspective on Dutch Agroecosystems: How Soil Organisms Interact to Support Ecosystem Services. Adv Ecol Res 44: $277-$ 357.

Neher, D.A., Wu, J., Barbercheck, M.E., Anas, O. 2005. Ecosystem type affects interpretation of soil nematode community measures. Applied Soil Ecology 30 : 47-64.

Pinto, T.K., Austen, M.C., Bemvenuti, C.E. 2006. Effects of macroinfauna sediment disturbance on nematode vertical distribution . Journal of the Marine Biological Association of the United Kingdom 86 : 227-233.

Treonis, A.M. and Wall, D.H. 2005. Soil nematodes and desiccation survival in the extreme arid environment of the Antarctic dry valleys. Integr Comp Biol 45: 741-750.

Tsiafouli, M.A., Argyropoulou, M.D., Stamou, G.P., Sgardelis, S.P. 2007. Is duration of organic management reflected on nematode communities of cultivated soils? Belgian Journal of Zoology 137: 165-175.

Verschoor, B.C., DeGoede, R.G.M., deHoop, J.W., deVries, F.W.2001. Seasonal dynamics and vertical distribution of plant-feeding nematode communities in grasslands, Pedobiologia 45 :213-233.

Wall, D.H. 2012. Soil Ecology and Ecosystem Services (eds Wall DH, Bardgett RD, Behan-Pelletier V, Herrick JE, Jones H, Ritz K,et al. Oxford: Oxford University Press. 424 p.

Wasilewska, L. 1994. The effect of age of meadows on succession and diversity in soil nematode communities. Pedobiologia 38: 1-11.

Wu, T.H., Ayres E., Bardgett, R.D., Wall, D.H., Garey, J.R. 2011. Molecular study of worldwide distribution and diversity of soil animals. Proc Natl Acad Sci USA 108: 17720-17725.

Yeates, G. 2003. Nematodes as soil indicators: functional and biodiversity aspects. Biology and Fertility of Soils 37: 199-210.

Yeates, G.W. 2007. Abundance, diversity, and resilience of nematode assemblage in forest soils, Can. J. For. Res. 37 : 216-225.

Yeates, G.W., Bongers, T., De Goede, R.G.M., Freckman D.W., Georgieva, S.S. 1993. Feeding-Habits in Soil Nematode Families and Genera - an Outline for Soil Ecologists. J Nematol 25: 315-331.

Zhao, J., Neher, D.A. 2013. Soil nematode genera that predict specific types of disturbance. Appl Soil Ecol 64: 135-141.

Nepalese Journal of Zoology | Online Volume 3 Issue 1 | November 2015 | Page 62 